A.V. Dobromyslov

Institute of Metal Physics, Ural Branch of Russian Academy of Sciences, Ekaterinburg, Russia

\title{
THE REGULARITIES OF PHASE AND STRUCTURAL TRANSFORMATION IN BINARY TITANIUM ALLOYS WITH METALS OF IV-VIII GROUPS OF THE PERIODIC TABLE
}

\begin{abstract}
Martensitic $\beta \rightarrow \alpha^{\prime}\left(\alpha^{\prime \prime}\right)$ and $\beta \rightarrow \omega$ transformation in a series of Ti-base alloys with transition metals of groups IV-VIII have been investigated using the techniques of X-ray diffraction, optical and transmission electron microscopy. Phase and structural information is given on the non-equilibrium and metastable modifications occurring in these alloys during quenching from high-temperature $\beta$-field and aging. The conditions of the orthorhombic $\alpha^{\prime \prime}$-phase, $\omega$-phase and metastable $\beta$-phase formation in binary titaniumbase alloys with $d$-metals of V-VIII groups were investigated. It was established that the position of the alloying metal in the Periodic Table defines the presence or absence of the $\alpha^{\prime \prime}$-phase in the alloy after quenching and the minimum concentration of the alloying metal necessary for formation of the $\alpha^{\prime \prime}$-phase, $\omega$-phase and metastable $\beta$-phase.
\end{abstract}

Key words: titanium alloys; phase transformation; $\alpha^{\prime \prime}$-phase; $\omega$-phase; metastable $\beta$-phase

\section{INTRODUCTION}

The determination of the general regularities of the phase and structural formation in the titanium-base alloys in depending on position of the alloying metal in the Periodic Table is one of the important task of the phase transformation theory. Binary titanium alloys with $d$-metals of 4-6 periods are excellent model objects for establishing general regularities regarding the formation of non-equilibrium and metastable phases. In binary titanium-base alloys rapidly quenched from the $\beta$-phase, martensite transformation can occur independently of the type of the equilibrium phase diagram. Two martensitic phases, $\alpha^{\prime}$ or $\alpha^{\prime \prime}$, are formed in quenched titanium-base alloys. The type of martensite crystal structure is determined by the composition of the alloy. At a certain concentration of the alloying element the $\beta$-phase is retained in quenched titanium alloys as a metastable phase. Up to now the effect of the alloying element type on the compositional boundaries of the non-equilibrium and metastable phases formation has been studied insufficient. However, the determination of the concentration fieldes of the $\alpha^{\prime \prime}$-, $\omega$ - and metastable $\beta$-phases is very important for the establishment of the general regularities regarding the formation of non-equilibrium and metastable phases. The purpose of the present research was to study the phase constitution of binary titanium- 
base alloys with $d$-metals of 4-6 periods (IV-VIII groups) and to establish the relation between features of phase formation of these alloys and the position of the alloying element in the Periodic Table.

\section{EXPERIMENTAL PROCEDURE}

We studied binary titanium-base alloys containing different amount of $\mathrm{V}, \mathrm{Cr}, \mathrm{Mn}, \mathrm{Fe}$, $\mathrm{Co}, \mathrm{Ni}, \mathrm{Cu}, \mathrm{Nb}, \mathrm{Mo}, \mathrm{Ru}, \mathrm{Rh}, \mathrm{Pd}, \mathrm{Ta}, \mathrm{W}, \mathrm{Re}, \mathrm{Os}, \mathrm{Ir}, \mathrm{Pt}$ and $\mathrm{Zr}$. The alloys were prepared from iodide Ti (99,96 wt.\%), V (99,7 wt.\%), Cr (99,95 wt.\%), Mn (98,53 wt.\%), Fe (99,84 wt.\%), Co (99,98 wt.\%), Ni (99,99 wt.\%), Cu (99,99 wt.\%), Nb (99,6 wt.\%), Mo (99,9 wt.\%), Ru (99,9 wt.\%), Rh (99,9 wt.\%), Pd (99,91 wt.\%), Ta (99,5 wt.\%), W $(99,95$ wt.\%), Re (99,9 wt.\%), Os $(99,99$ wt.\%), Ir (99,9 wt.\%), Pt (99,9 wt.\%). All alloys were melted in a tungsten-arc furnace under a helium atmosphere. The specimens were homogenised in the $\beta$-phase region $\left(1000\right.$ or $\left.1100^{\circ} \mathrm{C}\right)$ and quenched from these temperatures in iced or brine water.

\section{RESULTS AND DISCUSSION}

\section{Formation of the $\alpha^{\prime \prime}$-phase}

The optical and transmission electron microscope studies show that quenched binary titanium-base alloys with low content of the alloying element have a martensite structure. Two martensite phases, $\alpha^{\prime}$ and $\alpha^{\prime \prime}$, are formed. The transition from hexagonal $\alpha^{\prime}$-phase to orthorhombic $\alpha^{\prime \prime}$-phase occurs under a certain concentration of alloying metal. The compositional limit of the $\alpha^{\prime \prime}$-phase formation depends on the type of the alloying metal. Figure 1 shows the $\mathrm{X}$-ray diffraction patterns of titanium-base alloys with minimum or close to minimum concentration of alloying metal, at which the orthorhombic $\alpha^{\prime \prime}$-phase is formed in the alloys after quenching. In accordance with the data obtained in previous works [1-4] we were revealed the $\alpha^{\prime \prime}$-phase in quenched Ti-V, Ti-Nb, Ti-Ta, Ti-Mo, Ti-W, Ti-Re, and Ti-Ru alloys. Besides, we were established that the $\alpha^{\prime \prime}$-phase is formed also in quenched binary titanium-base alloys with iridium and osmium. The formation of the orthorhombic $\alpha^{\prime \prime}$-phase in the titanium-base alloys with other alloying metals of V-VIII groups was not observed. Table 1 summarised results obtained in the course of this study.

The analysis of data presented in the table 1 allows finding out a number of general rules, characterising the formation of the $\alpha^{\prime \prime}$-phase in binary titanium-base alloys. The formation of the $\alpha^{\prime \prime}$-phase in quenched alloys depends on the position of alloying metal in the Periodic Table. Both the group number and the periodic number influence on the conditions of the $\alpha^{\prime \prime}$-phase existence in the alloys. In the alloys with alloying metals of 4-th period, the $\alpha^{\prime \prime}$-phase is formed only in the Ti-V alloy. In the alloys with metals of the 5-period the presence of the $\alpha^{\prime \prime}$-phase was established in the Ti-Nb, Ti-Mo, and $\mathrm{Ti}-\mathrm{Ru}$ alloys. With metals of the 6-period the $\alpha^{\prime \prime}$-phase is formed in the all alloys from 
tantalum to iridium. Thus, the orthorhombic $\alpha^{\prime \prime}$-phase is formed in all binary titanium alloys the alloying metals of which are located in the Periodic Table below line drawn from chromium to platinum.
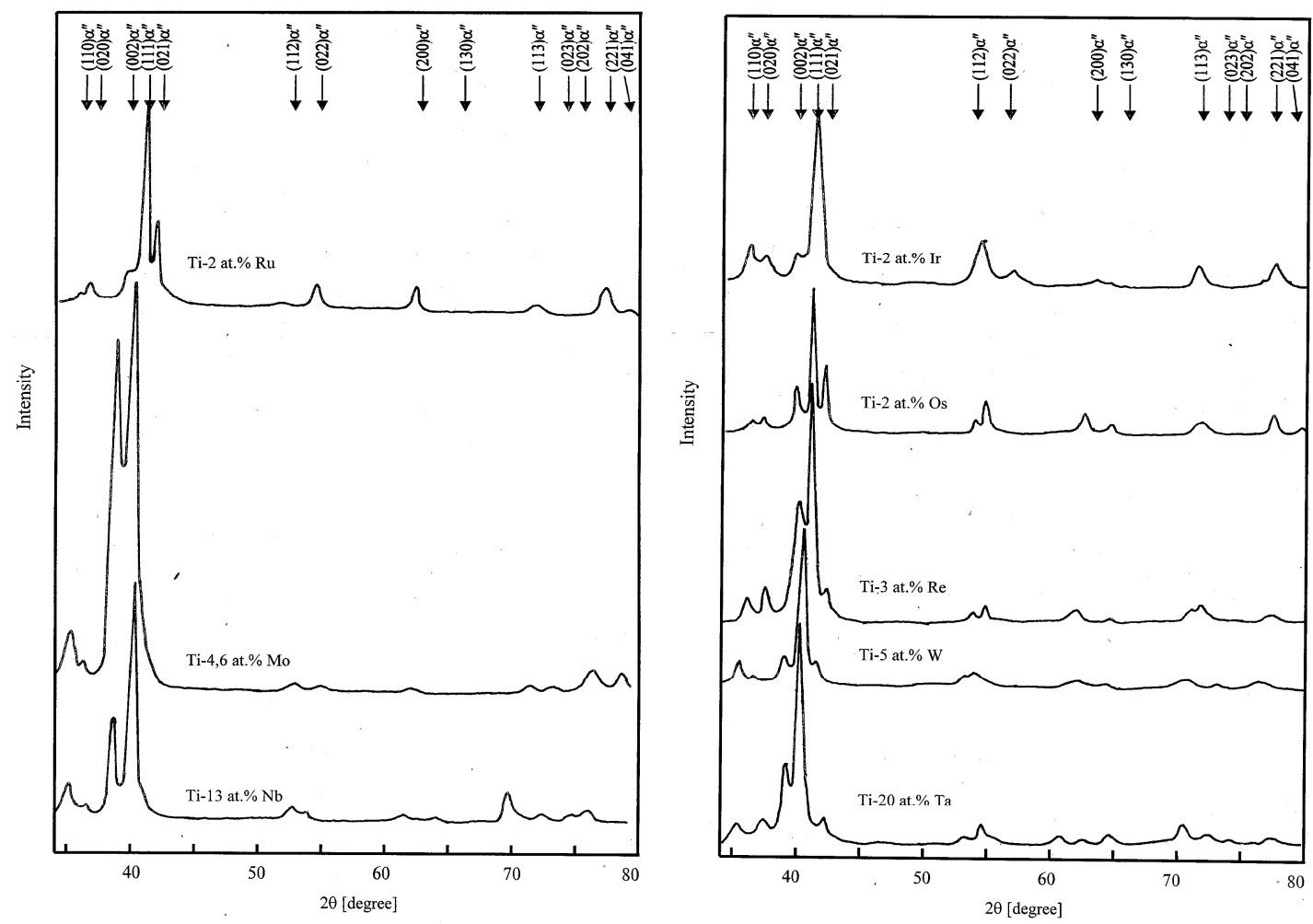

Fig.1. X-ray diffraction patterns of different binary titanium-base alloys, showing the $\alpha^{\prime \prime}$-phase peaks

Table 1. Minimum concentration of the alloying metal necessary for the formation of the orthorhombic $\alpha^{\prime \prime}-$ phase in binary titanium alloys, at.\%

\begin{tabular}{|c|c|c|c|c|c|c|c|}
\hline IVA & VA & VIA & VIIA & \multicolumn{3}{|c|}{ VIIIA } & IB \\
\hline $\mathbf{T i}$ & $\begin{array}{c}\mathrm{V} \\
\alpha^{\prime \prime} \\
9\end{array}$ & Cr & $\begin{array}{l}\mathrm{Mn} \\
-\end{array}$ & $\begin{array}{l}\mathrm{Fe} \\
-\end{array}$ & Co & $\mathrm{Ni}$ & $\stackrel{\mathrm{Cu}}{-}$ \\
\hline $\begin{array}{l}\mathrm{Zr} \\
-\end{array}$ & $\begin{array}{l}\mathrm{Nb} \\
\alpha^{\prime \prime} \\
11\end{array}$ & $\begin{array}{c}\text { Mo } \\
\alpha^{\prime \prime} \\
4-5 \\
\end{array}$ & $\begin{array}{c}\text { Tc } \\
\alpha^{\prime \prime} \\
?\end{array}$ & $\begin{array}{c}\mathrm{Ru} \\
\alpha^{\prime \prime} \\
2 \\
\end{array}$ & $\begin{array}{l}\mathrm{Rh} \\
-\end{array}$ & $\begin{array}{l}\mathrm{Pd} \\
-\end{array}$ & $\begin{array}{c}\mathrm{Ag} \\
?\end{array}$ \\
\hline $\begin{array}{l}\mathrm{Hf} \\
-\end{array}$ & $\begin{array}{l}\text { Ta } \\
\alpha^{\prime \prime} \\
15\end{array}$ & $\begin{array}{c}\mathrm{W} \\
\alpha^{\prime \prime} \\
5\end{array}$ & $\begin{array}{c}\mathrm{Re} \\
\alpha^{\prime \prime} \\
3\end{array}$ & $\begin{array}{c}\text { Os } \\
\alpha^{\prime \prime} \\
2\end{array}$ & $\begin{array}{c}\mathrm{Ir} \\
\alpha^{\prime \prime} \\
2\end{array}$ & $\stackrel{\mathrm{Pt}}{-}$ & $\begin{array}{c}\mathrm{Au} \\
?\end{array}$ \\
\hline
\end{tabular}

\section{Formation of metastable $\beta$-phase}

The X-ray diffraction study shows that the $\beta$-phase is retained in rapidly quenched titanium alloys at a certain concentration of the alloying metal. Table 2 summarised results obtained in the course of this study on compositional limit for the complete stabilisation of metastable $\beta$-phase in quenched titanium-base alloys. The titanium 
alloys are arranged in the table 2 according to the position of the alloying metal in the Periodic Table.

Table 2. Minimum concentration of the alloying element necessary for the complete stabilization of the $\beta$ phase in binary titanium alloys with d-metals of 4-6 periods, at.\%

\begin{tabular}{|c|c|c|c|c|c|c|}
\hline $\mathrm{Ti}-\mathrm{V}$ & $\mathrm{Ti}-\mathrm{Cr}$ & $\mathrm{Ti}-\mathrm{Mn}$ & $\mathrm{Ti}-\mathrm{Fe}$ & $\mathrm{Ti}-\mathrm{Co}$ & $\mathrm{Ti}-\mathrm{Ni}$ & $\mathrm{Ti}-\mathrm{Cu}$ \\
\hline 15 & 7 & 6 & 5 & 7 & 9 & 11 \\
\hline $\mathrm{Ti}-\mathrm{Nb}$ & $\mathrm{Ti}-\mathrm{Mo}$ & $\mathrm{Ti}-\mathrm{Tc}$ & $\mathrm{Ti}-\mathrm{Ru}$ & $\mathrm{Ti}-\mathrm{Rh}$ & $\mathrm{Ti}-\mathrm{Pd}$ & $\mathrm{Ti}-\mathrm{Ag}$ \\
\hline 23 & 5 & $?$ & 3 & 4 & 11 & $?$ \\
\hline $\mathrm{Ti}-\mathrm{Ta}$ & $\mathrm{Ti}-\mathrm{W}$ & $\mathrm{Ti}-\mathrm{Re}$ & $\mathrm{Ti}-\mathrm{Os}$ & $\mathrm{Ti}-\mathrm{Ir}$ & $\mathrm{Ti}-\mathrm{Pt}$ & $\mathrm{Ti}-\mathrm{Au}$ \\
\hline $35(30)$ & 10 & 5 & 3 & 3 & 7 & $?$ \\
\hline
\end{tabular}

The analysis of data presented in the table 2 allows finding out a number of general regularities, characterising the forming of metastable $\beta$-phase in binary titanium-base alloys. Both the group number and the period number influence on the minimum concentration of the alloying metal necessary for the complete stabilisation of the $\beta$ phase in quenched alloy. In 4-th period, $\beta$-stabilising effect of the alloying metal increases with increasing the group number from vanadium up to iron, and then it decreases from cobalt up to copper. In the Ti-Fe alloys the complete stabilisation of the $\beta$-phase occurs at the lesser concentration of the alloying metal. Similar change of the minimum concentration of the alloying metal necessary for the complete stabilisation of metastable $\beta$-phase is observed in binary titanium-base alloys with the alloying metals of 5-th and 6-th periods. The largest concentration of the alloying metal necessary for the complete stabilisation of the $\beta$-phase during quenching is observed in the $\mathrm{Ti}-\mathrm{Ta}$ alloys and it is 35 at.\%. The lesser concentration of the alloying metal necessary for the complete stabilisation of the $\beta$-phase is observed in the Ti-Ru, Ti-Os, and Ti-Ir alloys, and it is 3 at. $\%$.

The concentration limit of the alloying metal, at which the complete stabilisation of metastable $\beta$-phase occurs, can be expressed through number of electrons per atom. These values are changed in sufficiently broad range from 4,1-4,12 e/a (Ti-V, Ti-Mo, $\mathrm{Ti}-\mathrm{Os}$ and $\mathrm{Ti}-\mathrm{Ir}$ alloys) up to 4,76 e/a ( $\mathrm{Ti}-\mathrm{Cu}$ alloy). According to [2-4] the electronto-atom ratio necessary for the complete stabilisation of the $\beta$-phase at room temperature is $\sim 4,2$. However, the data obtained in this study indicate that the electronto-atom ratio, at which the complete stabilization of the $\beta$-phase occurs in binary titanium-base alloys with transition metals, has not a constant value.

Up to now the correlation between the $\mathrm{M}_{\mathrm{s}}$ temperatures of binary titanium-base alloys and the position of alloying elements in the Periodic Table are not established. The minimum concentration of the alloying metal, at which the complete stabilization of the $\beta$-phase take place, allows to determine the $M_{s}$ curve position of every alloy at room temperature. So we can use such data to arrange the $M_{s}$ curves, obtained for different alloys [5, 6], depending on the group number of the alloying metal. Figure 2 shows the $\mathrm{M}_{\mathrm{s}}$ curves for titanium-base alloys with the alloying metals of 4,5 , and 6 periods. We can see that the identical change of the $M_{s}$ curves with the increase of the group number is observed for titanium-base alloys with the alloying metals of all three periods. The increase of the group number of the alloying metal primary leads to decreasing the $\mathrm{M}_{\mathrm{s}}$ temperatures. However, when crystal structure of the alloying metal becomes FCC, the increase of the $M_{s}$ curves occurs with increasing the group number of the alloying metal. Similar behavior of the $\mathrm{M}_{\mathrm{s}}$ curves of titanium-base alloys of all three periods 
testifies that the position of the alloying metal in the Periodic Table is essential factor, which determines the process of martensitic $\beta \rightarrow \alpha^{\prime}\left(\alpha^{\prime \prime}\right)$ transformations. For alloying metals with BCC structure, the $\mathrm{M}_{\mathrm{s}}$ temperatures decrease the stronger the greater the group number, and opposite, for alloying metals with FCC structure, the $M_{s}$ temperatures decrease the stronger the lesser the group number.

Thus, for binary titanium-base alloys the position of the alloying metal in the Periodic Table defines the minimum concentration of the alloying metal necessary for complete stabilization of the $\beta$-phase during quenching, and the shape of the $\mathrm{M}_{\mathrm{s}}$ curves.
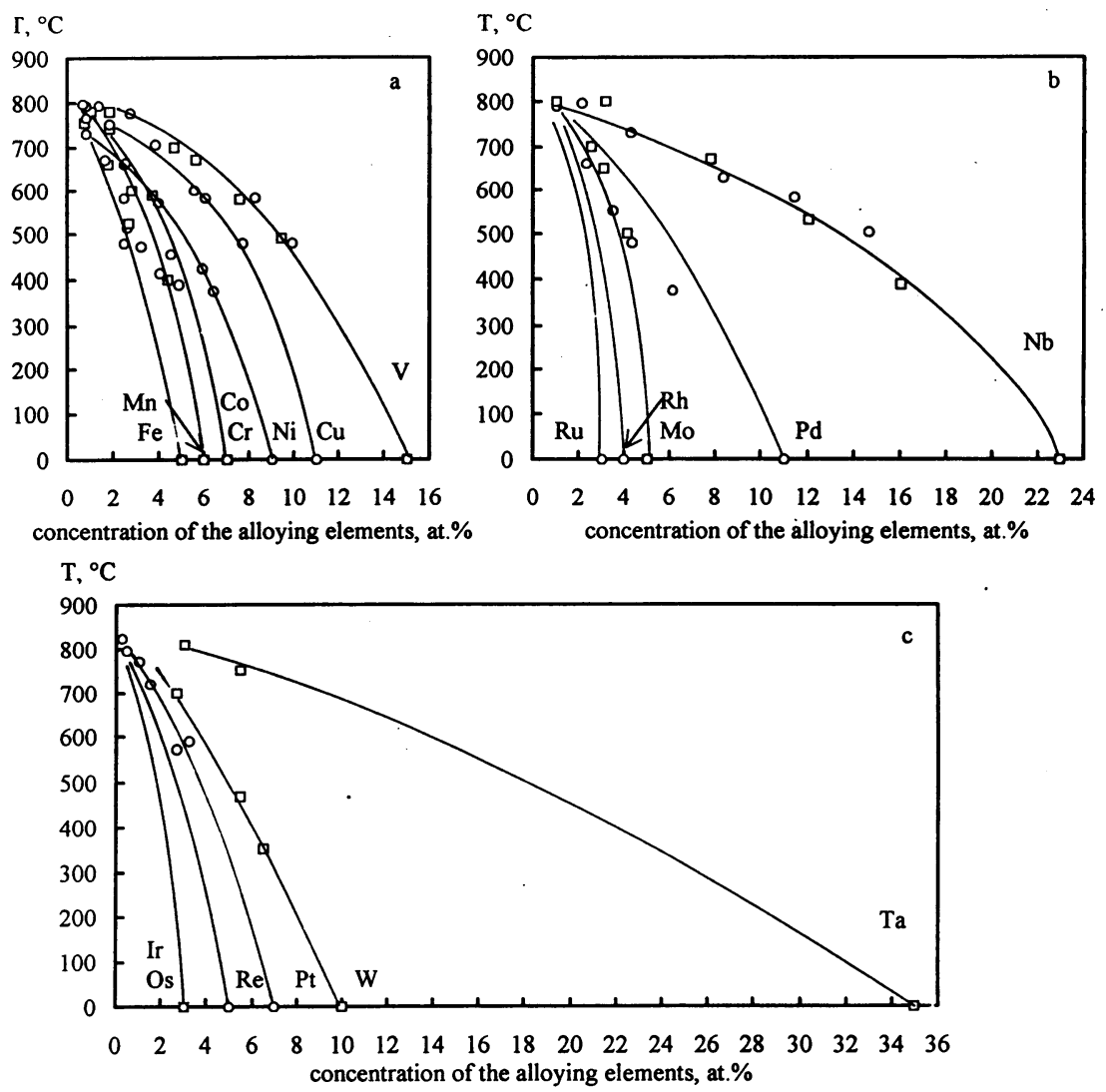

Fig.2. The $M_{s}$ point of titanium as a function of alloying additions for: $a-4$ period; $b-5$ period; $c-6$ period (square for $M_{s}$ point at high temperature [5]; circle for $M_{s}$ point at high temperature [6]; $M_{s}$ point at temperature $0^{\circ} \mathrm{C}$ ccording to our date)

\section{Formation of $\omega$-phase}

As mentioned above, the $\beta$-phase is retained in titanium-base alloys in a metastable state after rapid cooling. No evidence for the occurrence of the athermal $\omega$-phase is found by X-ray diffraction in this case. Formation of the $\omega$-phase depends on quenching rate. It is formed in many titanium-base alloys with transition metals of 4-6 periods in slowly quenched specimens. In $\mathrm{Ti}-\mathrm{Nb}, \mathrm{Ti}-\mathrm{Ta}, \mathrm{Ti}-\mathrm{W}$ and $\mathrm{Ti}-\mathrm{Re}$ systems, the $\omega$-phase is observed only after ageing in the temperature range 300 to $500^{\circ} \mathrm{C}$. Figure 3 illustrates morphology of the $\omega$-phase in some titanium-base alloys. The particles of the $\omega$-phase in the $\mathrm{Ti}-\mathrm{V}, \mathrm{Ti}-\mathrm{Cr}, \mathrm{Ti}-\mathrm{Mn}, \mathrm{Ti}-\mathrm{Fe}, \mathrm{Ti}-\mathrm{Co}, \mathrm{Ti}-\mathrm{Ni}, \mathrm{Ti}-\mathrm{Rh}$ alloys have ellipsoidal morphology. The particles of the $\omega$-phase in the $\mathrm{Ti}-\mathrm{Nb}$, Ti-Mo and $\mathrm{Ti}-\mathrm{Re}$ alloys have cubical morphology. Electron diffractions studies show that it is observed a continuous change in diffraction patterns with increasing content of alloying metal in the alloy. The 
$\omega$-phase has sharp reflections in low solute content alloys and diffuse reflections in high solute content alloys.
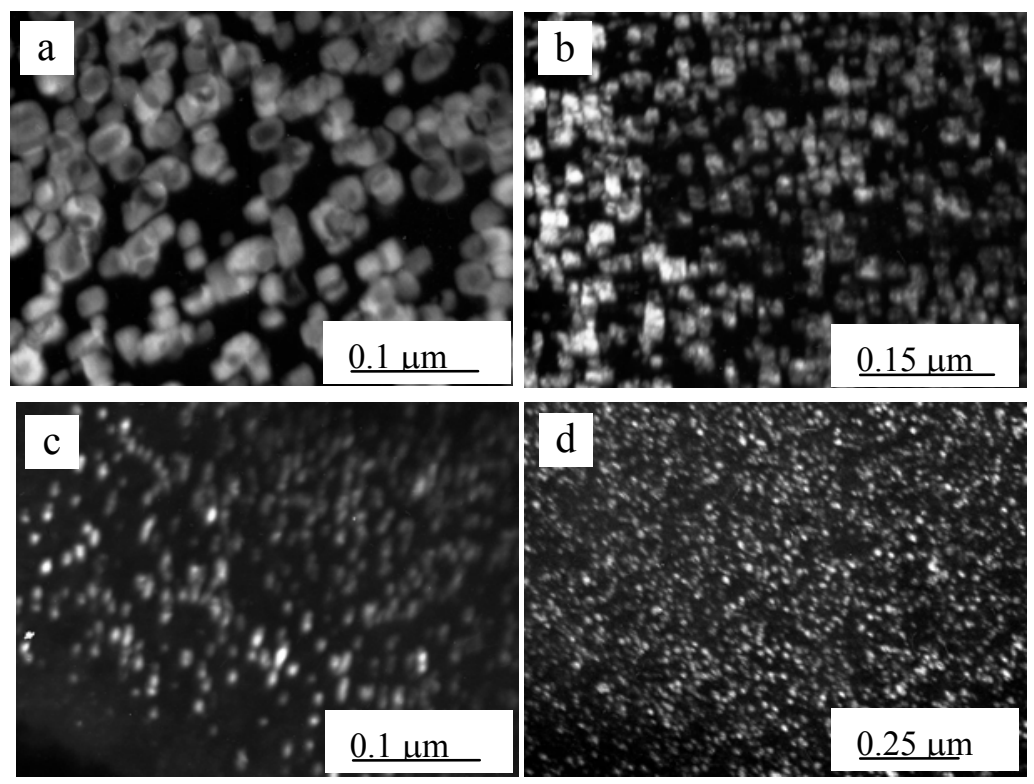

Fig.3. Dark-field images of $\omega$-particles in titanium-baase alloys after ageing: a - Ti-5 at. $\% \mathrm{Fe}, 400^{\circ} \mathrm{C}$ $-1000^{\prime}$; b- Ti-7 at. $\%$ Co, $400^{\circ} \mathrm{C}-178^{\prime}$; c- Ti-35 at. $\%$ Ta, $400^{\circ} \mathrm{C}-562^{\prime}$; d - Ti-7 at. $\%$ Re, $400^{\circ} \mathrm{C}-562^{\prime}$

\section{CONCLUSIONS}

The structure of titanium-base alloys with $d$-metals of V-VIII, I groups of the Periodic Table, quenched from $\beta$-phase region, was studied. It was established the effect of the position of the alloying metal in the Periodic Table on the formation conditions of the orthorhombic $\alpha^{\prime \prime}$-phase and metastable $\beta$-phase. It is established that in quenched alloys the $\omega$ phase is formed in all titanium-base alloys with d-metals of V-VIII groups of the Periodic Table.

\section{REFERENCES}

1. Nosova G.I.: Phase transformations in titanium alloys. Metallurgia, Moskow, 1964.

2. Kolachev B.A., The physical metallurgy of titanium, Moskow, Metallurgia,1976.

3. Collings E.W.: The physical metallurgy of titanium alloys, Metallurgia, Moskow, 1988.

4. Zwicker U.: Titan und Titan legierungen. Springer-Verlag Berlin, Heidelberg, New York, 1974.

5. Duwez P.: Trans. ASM, 45, 934 (1953).

6. Kaneko H., Huang, Y.C. J. Japan Inst. Metals, 27, 387 (1963). 